\title{
Jeremy Safran's impact on Italian psychotherapy research and practice: a window into the processes involved in therapeutic alliance
}

\author{
Francesca Locati, ${ }^{1}$ Franco Del Corno, ${ }^{2}$ Laura Parolin ${ }^{1}$ \\ ${ }^{1}$ Department of Psychology, University of Milan-Bicocca, Milan; ${ }^{2}$ SPR-Italy Area Group, Milan, Italy
}

Jeremy Safran made a major contribution to contemporary psychotherapy both as a scientist and as a clinician. This contribution is somehow hard to summarize given the vastness of the issues he explored and drastically affected, and it definitely goes far beyond the research, technical or theoretical fields alone. Safran, indeed, provided us a new conceptualization of psychotherapy work itself, in which the therapist and the patient and their hic et nunc (i.e., here and now) intersubjective dynamics are conceived as the multilevel core of the treatment. This new conceptualization has represented a revolutionary step in the psychotherapy literature, as we outline below.

The impact on the literature was reached by continuous and progressive work on the concept of the therapeutic alliance. Therapeutic alliance was previously defined as an

Correspondence: Laura Parolin, Department of Psychology, University of Milan-Bicocca, Piazza Ateneo Nuovo 1, 20126 Milano, Italy.

Tel./Fax: +39.02.64483796

E-mail: laura.parolin@unimib.it

Citation: Locati, F., Del Corno, F., \& Parolin, L. (2019). Jeremy Safran's impact on Italian psychotherapy research and practice: a window into the processes involved in therapeutic alliance. Research in Psychotherapy: Psychopathology, Process and Outcome, 22(1), 15-18. doi: 10.4081/ripppo.2019.357

Key words: Therapeutic alliance; Therapeutic process; Intersubjective negotiation process; Interpersonal cycle.

Contributions: the authors contributed equally.

Conflict of interest: the authors declare no potential conflict of interest.

Funding: none.

Received for publication: 6 December 2018.

Revision received: 21 February 2019.

Accepted for publication: 22 February 2019.

This work is licensed under a Creative Commons Attribution NonCommercial 4.0 License (CC BY-NC 4.0).

(C) Copyright F. Locati et al., 2019

Licensee PAGEPress, Italy

Research in Psychotherapy:

Psychopathology, Process and Outcome 2019; 22:15-18

doi:10.4081/ripppo.2019.357 interactive process between the patient and the clinician based on their ability to create a respectful and cooperative bond. Safran and Muran (2000) critically refined the concept of alliance by drifting from the construct of "agreement" to the idea of "negotiation" between therapist and patient. Under this view, alliance was no longer conceived as a static dimension necessary to establish an effective intervention but rather as a constantly shifting, emergent property of the therapeutic relationship (Safran \& Muran, $2000,2006)$. Therefore, therapeutic alliance was interpreted as an intersubjective negotiation process, where rupture moments became the new core element of the therapeutic process. Accordingly, rupture moments were defined as "a breakdown in the collaborative process between therapist and patient, a poor quality of therapistpatient relatedness, a deterioration in the communicative situation, or a failure to develop a collaborative process from the outset" (Safran \& Muran, 2006, p. 288). As a consequence, ruptures became an essential element as a "window on the relational schemas of the patient" or, rather, as the opportunity to investigate and better understand the patient's mental functioning. The types of ruptures (withdrawn or confrontation ruptures) most frequently adopted by the patient reflect his/her coping strategy or a feature of their psychic functioning. As a consequence, correctly identifying ruptures can guide the therapist's interventions to repair them (Safran \& Muran, 2000).

Under this framework, the therapeutic process was reformulated as a coparticipation in the therapeutic dyad in the negotiation composed of the continuous sequence of rupture and resolution phenomena. Following this rationale, resolving ruptures implies intervening and reorganizing the relational schemas of the patient (Safran \& Muran, 2000); the negotiation process represents, therefore, the therapeutic changing process. Through the therapeutic work on therapeutic alliance, in Safran's theory, the therapist can intervene on the patient's interpersonal experience often characterized by maladaptive patterns. This process might lead to a positive "interpersonal cognitive cycle" (Safran \& Segal, 1990).

The impact of this new conceptualization has been tremendous and is currently reflected at different levels. On a theoretical level, the therapeutic process has been reformulated under an intersubjective perspective as a "specific psychological field" created by the interplay be- 
tween the patient's and therapist's subjectivities. On a clinical level, alliance rupture and resolution processes have been technically interpreted as a focused way of working on patients' maladaptive patterns in the hic et nunc of therapeutic relationships. Finally, on a scientific level, the construct of therapeutic alliance became a core empirical variable that interacts with the other variables of the therapeutic process in an interactive methodological approach.

This wide contribution of Safran has helped to bridge the gap among theory, practice and research, opening new perspectives for the international scientific and clinical communities. Moreover, the reformulation of the therapeutic alliance as an intersubjective process leaves the alliance concept free from a specific theoretical model, formerly recognized in the ego psychology approach. In this way, therapeutic alliance can be flexibly adapted for any therapeutic approach.

Analogous to such an international impact, Safran's work has been an important influence on Italian psychotherapy clinical and research as well. In particular, the contribution of Safran's work arrived in the Italian psychodynamic context some years later.

At that time, following the "Dodo bird verdict", empirical research had attributed a growing interest in the therapeutic alliance, recognized as the nonspecific factor able to explain the variance in outcome, while psychoanalytic theorists had started to lose interest in the exploration of such concept (Safran \& Muran, 2000). This profound paradox was reflected in the Italian situation as well. On the one hand, the Italian psychoanalytic community tended to neglect the empirical evidence related to theory. On the other hand, also in Italian psychoanalytic theory, the therapeutic alliance was considered a nonspecific part of the therapeutic relationship. Vittorio Lingiardi identified the specific importance of Safran's theoretical role and made the greatest efforts to disseminate his contribution (Lingiardi, 2008). Different relevant books were developed on the therapeutic alliance (Lingiardi, 2002) and relational turn themes (Lingiardi, Amadei, Caviglia, $\&$ De Bei, 2011). Moreover, various articles disseminated the theoretical and clinical implications on these topics to the Italian clinical community in national journals (i.e., Setting, Ricerca in psicoterapia).

These contributions exerted a relevant influence on the Italian clinical psychotherapy community since the Safran therapeutic alliance model helped to bridge the gap between research and clinical fields, redefining the therapeutic alliance and giving specificity to this construct. These developments, in turn, supported the need for a deeper relational perspective and techniques in psychotherapy. Safran himself drew parallels between the American and Italian contexts and illustrated the specific merits of the Italian community in advancing the relational approach. This work also helped to promote an international collaboration between Lingiardi and Safran (e.g., Lingiardi, Holmqvist \& Safran, 2016), who emphasized the theoretical relevance of the role of the therapeutic alliance in its association with the concept of the relational turn in psychotherapy.

It is worth noting that the Safran intersubjective definition of therapeutic alliance also had an innovative impact on the pretreatment assessment: the revised version of the Psychodynamic Diagnostic Manual (PDM-2, Lingiardi \& McWilliams, 2017) indicated that all mental functioning capacities, i.e., defense mechanisms or reflective functioning, may have relevant effects in the process of "intersubjective negotiation" within the therapeutic dyad.

Moving from the aforementioned psychodynamic perspective, Safran also influenced Italian cognitive approaches and directly impacted the applicative level. Giovanni Liotti examined in depth the turning point in the conceptualization of the therapeutic alliance in relation to the evolutionary-cognitive perspective (Liotti \& Monticelli, 2014). Liotti brought into the Italian context the discussion on the intersubjective negotiation integrated with the cognitive tradition and attachment theory, with the aim of improving even the technical aspects of the therapeutic approach. More specifically, Liotti integrated the interpersonal dimension in his evolutionary-ethological approach to the study of human motivation. Thus, Liotti suggested that social interactions are based on basic motivational systems. Following a similar rationale, in the therapeutic relationship, there would be a correspondence between the rupture-resolution dynamics and the activation of different types of motivational systems. This suggestion provided the ground for empirical studies of the motivational processes that characterize the therapeutic relationship during the psychotherapy process and the creation of a specific assessment measure. In this context, Assessing Interpersonal Motivations in Transcripts (AIMIT) is a measure that assesses the determinants of change in psychotherapy, as well as of ruptures and reconstructions of therapeutic relationships (Liotti \& Monticelli, 2008).

In the Italian cognitive framework, Safran also inspired the metacognitive school. In Safran's view of psychotherapy intervention, the therapist may modify the patient maladaptive interpersonal patterns by the hic et nunc work in the relationship. This process can also be interpreted as an "interpersonal cycle", showing how the patient acts and reacts towards others, including the therapist, who is driven by well-consolidated intrapsychic structures, i.e., "interpersonal schemes", which contain the subjective representations of the fate of or his/her desires in the relationship with others (Safran \& Muran, 2000). Italian cognitive authors, inspired by this suggestion, integrated this dimension into metacognitive theory and techniques, such as metacognitive interpersonal therapy (Dimaggio, Montano, Popolo, \& Salvatore, 2015). Metacognitive system dysfunctions, in fact, can explain a variety of pathological forms; deficits in metacognition, 
for example, may block the expression of emotions and the decision-making process, impeding in turn the correct recognition of others' feelings or intentions.

Lastly, Safran influence had a great impact on Italian psychotherapy research. Inspired by Safran's endeavor, researchers from the Sapienza University of Rome published various studies on the relationship between alliance and other dimensions on the therapeutic process. For instance, the most relevant empirical studies demonstrated that Cluster A patients have difficulty establishing therapeutic alliance, whereas therapists evaluate alliance with Cluster B patients negatively (Lingiardi, Filippucci, \& Baiocco, 2005) and that session quality predicts the therapeutic alliance (Lingiardi, Colli, Gentile, \& Tanzilli, 2011). Further, Colli and Lingiardi created a measure to assess the therapeutic alliance based on Safran and Muran's (2000) conceptualization: the Indice di Valutazione dell'Alleanza Terapeutica or the Collaborative Interaction Scale-Revised, in its last version (Colli, Gentile, Condino, \& Lingiardi, 2017). The theoretical and empirical findings from Lingiardi's group produced new suggestions on the role of the therapeutic alliance in psychotherapy. Indeed, it was suggested that the therapeutic alliance acts as an effector variable in a circular interactive model of the therapist-patient interaction: a platform that can promote a good balance of technical techniques and can move the relational dimension as a "therapeutic agent" (Lingiardi, Tanzilli \& Colli, 2008).

Inspired by these theoretical and methodological considerations, the group at the University of Milano-Bicocca was able to investigate the in-session interactions during therapy, interpreting the therapy process as a dynamic interaction between the patient and the therapist. By means of an interactive approach, the results highlight the central role of the therapeutic alliance in the dynamics of several constructs in treatment (Locati, De Carli, Tarasconi, Lang, \& Parolin, 2016; Locati, Rossi, \& Parolin, 2017). As a cornerstone of the entire therapy, the alliance is determined by the emotional and relational structure emergent from the intersubjective cycles of patient and therapist (Locati et al., 2017).

Safran's scientific activity emerged in a historical context in which Italian psychotherapists, mostly and traditionally oriented to treat neurotic diseases, started to encounter patients with personality disorders. Contact with this psychopathological field, where relational dysfunctions became much more critical than behavioral symptoms, gave rise to new clinical issues and difficulties at an international level (Henggeler \& Santos, 1997) but also at a national level (Orefice, 2002; Ruggiero, 2011). In this framework, Safran left us a new definition of the therapeutic alliance by transforming this construct, which moved from a monolithic, unchangeable, pretherapeutic patient factor to an instrument of change. Safran also gave us a therapeutic alliance taxonomy, which specified how to work in the clinical room and helped the Italian clinical community to understand and handle "difficult patients" from a new perspective. The legacy of Safran is so deep and wide that it still impacts the theoretical progress in clinical psychology, for instance in the exploration of alliance within a life cycle approach (i.e., with children, adolescents and older patients), in the study of its relationship with other variables of the therapeutic process or in forced psychotherapy (i.e., the treatment of patients with antisocial personality disorder).

The ultimate goal of grasping human complexity makes Safran's approach an ideal integrative model, conceived as a meeting point between the patient and the therapist, past and future relational memories, and intrapsychic and interpersonal worlds.

\section{References}

Colli, A., Gentile, D., Condino, V., \& Lingiardi, V. (2017). Assessing alliance ruptures and resolutions: Reliability and validity of the Collaborative Interactions Scale-revised version. Psychotherapy Research, 1-14.

Dimaggio, G., Montano, A., Popolo, R., \& Salvatore, G. (2015). Metacognitive interpersonal therapy for personality disorders: A treatment manual. New York: Routledge.

Henggeler, S. W., \& Santos, A. B. (1997). Introduction, overview, and commonalities of innovative approaches. In Innovative approaches for "difficult-to-treat" populations. Washington DC: American Psychiatric Association.

Lingiardi, V. (2002). L'Alleanza Terapeutica. Milano: Raffaello Cortina Editore.

Lingiardi, V. (2008). Jeremy David Safran: integrazione, emozione, qui e ora. Setting, 2(26), 1000-1006.

Lingiardi, V., Amadei, G., Caviglia, G., \& Bei, D. (2011). La svolta relazionale. Itinerari italiani. Milano: Raffaello Cortina Editore.

Lingiardi, V., Colli, A., Gentile, D., \& Tanzilli, A. (2011). Exploration of session process: Relationship to depth and alliance. Psychotherapy, 48(4), 391.

Lingiardi, V., Filippucci, L., \& Baiocco, R. (2005). Therapeutic alliance evaluation in personality disorders psychotherapy. Psychotherapy Research, 15(1-2), 45-53.

Lingiardi, V., Holmqvist, R., \& Safran, J. D. (2016). Relational turn and psychotherapy research. Contemporary Psychoanalysis, 1-38.

Lingiardi, V., \& McWilliams, N. (2017). Psychodynamic diagnostic manual: PDM-2. New York: Guilford Publications.

Lingiardi, V., Tanzilli, A., \& Colli, A. (2008). Interventi del terapeuta e interazioni collaborative: alcune riflessioni sui processi di rottura e riparazione dell'alleanza terapeutica. Setting 25, 29-51.

Liotti, G. \& Monticelli, F. (2008). I sistemi motivazionali nel dialogo clinico: il manuale AIMIT. Milano: Raffaello Cortina Editore.

Liotti, G., \& Monticelli, F. (2014). Teoria e clinica dell'alleanza terapeutica. Una prospettiva cognitivo-evoluzionista. Milano: Raffaello Cortina Editore.

Locati, F., De Carli, P., Tarasconi, E., Lang, M., \& Parolin, L. (2016). Beyond the mask of deference: exploring the relationship between ruptures and transference in a single-case 
study. Research in Psychotherapy: Psychopathology, Process and Outcome, 19(2), 79-91.

Locati, F., Rossi, G., \& Parolin, L. (2017). Interactive dynamics among therapist interventions, therapeutic alliance and metacognition in the early stages of the psychotherapeutic process. Psychotherapy Research, 1-11.

Orefice, S. (2002). La sfiducia e la diffidenza: metodologia clinica per $i$ casi difficili. Milano, Raffaello Cortina.

Ruggiero, G. M. (2011). Terapia cognitiva: una storia critica.
Milano: Raffaello Cortina.

Safran, J. D., \& Muran, J. C. (2000). Negotiating the therapeutic alliance: A relational treatment guide. New York, Guilford Press.

Safran, J. D., \& Muran, J. C. (2006). Has the concept of the therapeutic alliance outlived its usefulness? Psychotherapy: Theory, Research, Practice, Training, 43, 286-291.

Safran, J. D., \& Segal, Z. V. (1990). Cognitive therapy: An interpersonal process perspective. New York, Basic. 